\title{
Efficiency in Utilization of the Resources Allocated to Lower Level Health Facilities in Uganda: a Case Study of Health Centre IVs
}

\section{Expeditus Ahimbisibwe}

Principal Health Planner, Ministry of Health

Ezrah Trevor Rwakinanga ( $\square$ rwakikyeduc@gmail.com )

MPH Student, London School of Hygiene \& Tropical Medicine

Christine Tashobya Kirunga

Makerere University, School of Public Health

\section{Research Article}

Keywords: Efficiency Change, Data Envelopment Analysis, Health Centres Efficiency, Health, Health Financing, Uganda

Posted Date: October 11th, 2021

DOI: https://doi.org/10.21203/rs.3.rs-880857/v1

License: (c) (i) This work is licensed under a Creative Commons Attribution 4.0 International License. Read Full License 


\section{Abstract}

Background: Everyone has a right to quality life with good health of the household and, thus, health sector financing should be a top priority because when the population is healthy, it is very productive and wealthy. In Uganda, Health Centre IVs (HCIVs) created under Uganda National Minimum Health Care Package provide curative, prevention and promotion services. The efficiency of these HCIVs is as critical as people's health and this paper measures efficiency in utilization of resources allocated to them.

Methods: The study used Hospital and HCIV Census data for 2014 and health sector data for FY2015/16 reported by $\mathrm{MOH}$ in the Annual Health Sector Performance Report. STATA software was used to perform Data Envelopment Analysis for a preferred model was out-put oriented that optimizes variable returns to scale. In this way, efficiency scores for every HCIV were calculated. Also, a Tobit regression model was run to estimate the factors contributing to the adjusted inefficiency scores for HCIVs.

Results: Overall, $7 \mathrm{HCIVs} \mathrm{(23.3 \% )} \mathrm{were} \mathrm{operating} \mathrm{under} \mathrm{constant} \mathrm{returns} \mathrm{to} \mathrm{scale,} \mathrm{implying} \mathrm{that} \mathrm{they} \mathrm{were}$ efficient (both pure technical and scale efficiency) while the 19 (63.3\%) were operating under increasing returns to scale, implying that their health service outputs would increase by a greater proportion compared to any proportionate increase in health services if more inputs were added in the facility. Four HCIVs (13.3\%) were operating at decreasing returns to scale meaning an additional input to the HCIVs would produce a less proportional change of outputs. The study identified catchment population, average length of stay, bed occupancy rate, and outpatient department visits as a proportion of inpatient days as the main factors of efficiency among HCIVs.

Conclusions: This study has shown how Data Envelope Analysis methods can be applied at the HCIV level of the health system to gain an insight into variation in efficiency across health centers using routinely available data. And, with the majority of HCIVs operating at increasing returns to scale, it showed that there is a need to increase inputs like staff, medicines and beds to achieve the desired optimal scale in case of constant returns to scale.

\section{Introduction}

\section{Background}

Health service delivery is a major priority both at the international and national levels. At the international level, Goal 3 of the Sustainable Development Goals (SDGs) [1] aims to ensure health and well-being for all at all ages by improving general health for mothers and children while reducing prevalence of noncommunicable diseases, improving health coverage for all and ensuring that medicines and vaccines are accessed at affordable rates in good quality.

The Ugandan government has indicated the priority of population health in several documents and one of the objectives of the National Development Plan [2] is to contribute to the production of a healthy human capital through the provision of equitable, safe and sustainable health services. The National Health 
Policy [3] states the health system objective is to ensure universal access to quality Uganda National Minimum Health Care Package (UNMHCP) consisting of Promotive, Preventive, Curative and rehabilitative and palliative services to all prioritized diseases and conditions with emphasis to the vulnerable population. This is also echoed in the Health Sector Development Plan (HSDP 2014/15 2019/20) [4] whose goal is to accelerate movement towards Universal Health Coverage (UHC) with essential health and related services needed for the promotion of health and productive life.

To achieve these goals, mentioned above, means that hospitals, clinics, medicines, and doctors' services should be accessible, available, acceptable, and of good quality for everyone, on an equitable basis, where and when needed. Hospitals and Health centers at the lower levels of service delivery, therefore, become a vital part of any health care system and account for a large proportion of the government's budget in most African countries [5].

In low and middle-income countries, health facilities at lower levels, mainly in rural and semi-urban areas, continue to be the main providers of healthcare to the communities and in Uganda, they accounted for $14 \%$ of the government's health care budget [6]. The ability to measure and compare their performance within the context of efficient utilization of resources is an important step in beginning to address some of the health care challenges that exist in this region.

\section{Healthcare Services in Uganda}

In Uganda, the healthcare delivery system is made up of public facilities (government) owned as well as privately owned. The districts and health sub-districts are major players in delivering health services at their respective levels as the decentralization process equipped them to perform. The health services are structured with National Referral Hospitals (NRHs) at the top, followed by Regional Referral Hospitals (RRHs), General Hospitals, and Health Centres (HC IVs, HC IIIs, and HC IIs).

Health Centre level IV, run by a Senior Medical officer, which in addition to all the services provided at HC III, is intended to provide blood transfusion services and emergency surgical services, and comprehensive emergency obstetric care including caesarean sections. The key feature of the UNMHCP was that each Health Sub District, which has approximately 100,000 people, would have a hospital or HC IV. According to the Health Sub-district (HSD) concept, an HC IV is the first referral facility in HSD without a hospital (Government or PNFP). The total number of HC IVs is 206 of these $182(88 \%)$ are government, $17(8.2 \%)$ NGOs, and 7 (3.4\%) privately owned (MOH, 2014) [15].

While some health facilities operate as designed and expected, others do not meet the expectations for different reasons that might be financial, technical, or otherwise. This is even more visible in low and middle-income countries, who, have high-cost inputs, the inappropriate scale of service delivery, and inadequate staff remuneration [7] that combine to bring down the general health facility performance. The functionality of the HC IV, in Uganda, is determined by outputs from selected components of minimum service standards i.e. maternity (deliveries), inpatient, blood transfusions, theatre (Caesarean 
Section, major and minor surgeries), HIV/AIDS Counselling and Testing, Prevention of Mother to Child Transmission, Anti-Retroviral Therapy, and long term contraception and outpatient services.

HC IV performance has been assessed using the Standard Unit of Output. The assessment covered 196 Health Centre IVs that reported through the district health information system. In total, for FY 2015/16, HC IVs attended to 4,274,028 outpatients; conducted 170,670 deliveries; and admitted 526,206 patients. The average outpatient attended to was 21,988 , mean deliveries 748 , and mean admission 2,347 as obtained from $\mathrm{MOH}$ [8]. Using this criterion, $45 \%(88 / 196)$ of the HC IVs were "functional" meaning able to do a cesarean section. For blood transfusion, $36 \%(70 / 196)$ were able to provide this service. Those able to provide both caesarean section and blood transfusion were $29 \%$ (57/196) which, overall, show low functionality of HC IVs.

The Uganda National Health Policy [9] while emphasizing that the sector will aim at mobilizing resources that are sufficient for government programs in an equitable, efficient and transparent manner, also asserts that efficiency is not well addressed whether in mobilization process allocation to different facilities or in utilization to achieve intended outcomes. This desire to improve efficiency is being emphasized both in the short-term and long-term development plans of government as evidenced in the Health sector development plan [10]. For this to be achieved, therefore, information on the current level of efficiency in the delivery of the various health services and the drivers of inefficiency will be required and currently, there has been no study done on efficiency at the HC IV level.

In Uganda [11; 12], other developing countries [13], and developed countries [14], there have been studies that applied Data Envelopment Analysis (DEA) to measure efficiency in health facilities as well as in economic development. They however used data from hospitals big and small while they ignored health centers as independent facilities that deliver substantial healthcare services to the people, especially in Uganda. This study, therefore, will first add a knowledge brick to the efficiency literature and bring forward evidence for Uganda's health sector so that policymakers can utilize the findings for a well-developed policy.

\section{Methods}

\section{Summary}

This is an analytical study whose main focus is to assess the efficiency levels in the utilization of resources at the lower-level health facilities with data on $\mathrm{HC}$ IVs obtained from surveys by $\mathrm{MOH}$ [15]. We applied the Data Envelopment Analysis approach (output-oriented model with Variable Returns to Scale) in STATA was employed to calculate the efficiency scores for HC IVs in the sample. To estimate the factors that make impact on adjusted inefficiency scores of health centre IVs, a Tobit regression model was deemed fit and run.

To assess Health Facility (HF) performance at the aggregate level and to inform policy decisions, there has been increasing use of the DEA method in the computation of efficiency scores. The DEA was used to 
test the efficiency of $30 \mathrm{HC}$ IVs which were of different sizes and whose functionality was within the public domain both for-profit and not-for-profit. The scope of the analysis was to assess the technical efficiency and scale efficiency. The HF operations were represented employing an input-output model whereby each HF uses quantities of inputs to generate outputs in the form of services.

\section{Conceptual Framework}

Health centers specifically the HC IVs use multiple health system inputs (e.g. health workers, medicines and supplies, electricity, water, infrastructure) to produce multiple health service outputs (e.g. inpatient care, outpatient care, surgery, blood transfusion) through a production process. These inputs which are summarized as labor and capital, combine via medical and surgical care to produce outputs. While the ultimate goal of healthcare is the marginal change in the health status of the people, this is difficult to measure in most data sets and the intermediate outputs or the episodes of care like the number of cesarean section operations and outpatient visits usually become the primary study outputs.

Coelli T. et. al., (2005) [16] asserts that this production process, in health facilities, does not occur in a vacuum which means that it can be influenced by several environmental factors both internal and external to the health center and this may manipulate how efficiently the production process occurs. Kumbhakar and Lovell (2000) [17] add that these factors are theorized either to affect the production process itself or to influence directly the efficiency of the process.

Figure 1 depicts the relationship between health system inputs, the production process, and the outputs which then forms the framework for our study.

The issue of measuring efficiency especially in the health sector is cumbersome because the service provision process is intricate enough regarding the true measurement of health improvement of an individual. The procedure of technical efficiency is often applied to answer this question and takes inputto-output formations to determine the outcome.

When dealing with the issue of output-oriented technical efficiency, the concentration of an analyst is on how to scale-up the amount of outputs while keeping the amount of inputs used fixed. On the other hand, input-oriented technical efficiency focuses on reducing input quantities used without changing the number of outputs produced.

Frontier techniques and the rations which measure utilization level of hospitals can be employed to measure the performance of health centres basing on the production theory of microeconomics. Commonly used ratios include bed occupancy rate, turnover ratio, turnover interval, and an average length of stay. Frontier methods of efficiency measures include linear programming techniques (e.g. data envelopment analysis) and econometric techniques (e.g. production and cost functions).

Efficiency has been generally defined as the allocation of scarce resources that maximizes the achievement of aims [18] while efficiency analysis of a production or service unit refers to the 
comparison between the outputs and inputs used in the process of producing a product or service [19]. According to Zainal and Ismail [20], efficiency relates to how best a firm utilizes the inputs to produce the desired products or services (outputs), which is indicative of the success of the firm and this is supported by Farell [21] who sees efficiency as success in producing as large as possible output from a given set of inputs and thus, in general, efficiency measures how best the value for money is being obtained from resources available.

The conceptual discussion of measuring efficiency is attributed to Koopmans [22] while an empirical measure of efficiency was pioneered by Farell [21], who classified efficiency into the two components of technical efficiency (TE) and allocative efficiencies (AE), both of which constitute the components of economic efficiency [17]. The idea is that a production unit is technically efficient if it is no longer possible to produce more output using more of the available inputs [22] which means an optimal position between inputs and outputs.

The aim of technical efficiency measurement, therefore, is to avoid wastage of resources by using more inputs when the technological and other support mechanisms have reached their limit of output produced. By implication, there can be an output augmenting orientation or an input conserving orientation dimension to the analysis of technical efficiency as observed by Kumar and Gulati [33]. Technically inefficient producers could use the same inputs to produce more of at least one output or could produce the same outputs with less of at least one input. Technical Efficiency reveals the ability of firms to employ the 'best practice' in an industry, such that no more than a given level of output can be produced using the minimum level of input. On the other hand, allocative efficiency refers to the optimal combination of inputs and outputs at a given price.

The ability to combine inputs and/or outputs in optimal proportions in light of prevailing prices is the focus of allocative efficiency in a business entity and these are satisfactory for the first-order conditions that a production facility is assigned. As implied by Chen and Zhu (2011), allocation of resources is considered efficient when the output from the last unit of resources is the same for different DecisionMaking Units (DMUs) [34] or health centres in the case of this study. In the health context, efficiency is concerned with the relation between resource inputs (labour, capital, material, or equipment) and health outcomes (e.g. numbers of patients treated, lives saved). The existence of inefficiency is indicated by the possible reallocation of resources in a manner that increases health outcomes produced. The technical efficiency of a hospital or health facility refers to the physical relation between health resources (capital, labour, and materials) and health outcomes.

However, findings have shown that most health HCIVs are not functioning as expected in terms of the major services they are meant to provide including caesarean sections and blood transfusion services $(\mathrm{MOH}, 2015)[10 ; 15]$. This, therefore, calls for an examination of the challenges affecting the functionality of the HC IVs to provide a Minimum Health Care package. The question, therefore, is whether it is efficiency in resource utilization that is affecting the functionality of the lower-level facilities (HC IVs) or if there could be other factors that could be leading to the non-functionality of HC IVs. 


\section{Data Envelopment Analysis (DEA)}

Data Envelope Analysis methodology, originally proposed in (Charnes et al., 1978) [23], was used to assess the relative efficiency of several entities using a common set of commensurate inputs to generate a common set of commensurate outputs. The original motivation for Data Envelope Analysis was to compare the productive efficiency of similar organizations, referred to as Decision Making Units. The problem of assessing efficiency is formulated as a task of fractional programming, but the application procedure for Data Envelope Analysis consists of solving linear programming (LP) tasks for each of the units under evaluation.

The efficiency of a Decision-Making Unit (DMU) is measured relative to all other Decision-Making Units with the simple restriction that all Decision-Making Units lay on or below the extreme frontier. Differing from other methods like regression equations that require any assumptions on their functional forms, Data Envelope Analysis is non-parametric in nature.

DEA was also used to calculate the efficiency scores for each of the health centers in the sample. The efficiency scores for each DMU (health centre) was tested through an out-put-oriented model that focussed of returns to scale that were variable using STATA software and was in the same sense used by Mujasi et al (2016) [12]. The VRS model estimated the pure technical efficiency and scale efficiency for each of the sample health centers. From the VRS model, analysis was made to establish whether an HC IV's production frontier indicated increasing returns to scale, constant returns to scale, or decreasing returns to scale.

Since not all health centres are functioning optimally, there was a need to look at variable returns to scale of each DMU so that the model chosen matches the reality of HCIVs in the country. Also, given the existence of unmet needs and low quality of care in developing countries like Uganda, there was a need to analyse the efficiency amounts that can be potentially saved and thus be used to escalate healthcare provision positively at health centre level as Mujasi et al (2016) [12] did for hospitals in Uganda.

On the flip side, however, it has been found that researchers have been reluctant to use Data Envelope Analysis as an analysis tool since it lacks a crucial error term (Valdmanis, 1992) [24]. However, a functional form was not the main goal or concern of this study but rather making the right mix between inputs and outputs for a health facility because DEA utilizes linear programming techniques to solve the service provision mix.

Data Envelope Analysis methodology, originally proposed in (Charnes et al., 1978) [23], was used to assess the relative efficiency of many entities using a common set of commensurate inputs to generate a common set of commensurate outputs. The original motivation for Data Envelope Analysis was to compare the productive efficiency of similar organizations, referred to as Decision Making Units. The problem of assessing efficiency is formulated as a task of fractional programming, but the application procedure for Data Envelope Analysis consists of solving linear programming (LP) tasks for each of the units under evaluation. 
Assuming that there are $\mathrm{j}$ health centers, each with $\mathrm{n}$ inputs and $\mathrm{m}$ outputs, the relative efficiency score of a given health center $(\theta)$ is obtained by solving the following output-orientated DEA (Charnes et al., 1978) [23] linear programming model;

Maximize $\theta_{0}=U_{1} Y_{1_{0}}+U_{2} Y_{2_{0}}+\mathrm{K}+U_{r} Y_{r_{0}}=\sum_{r=1}^{s} U_{r} Y_{r_{0}}$

Subject to the constraints that:

$v_{1} x_{1_{0}}+v_{2} x_{2_{0}}+\mathrm{K}+v_{m} x_{m_{0}}=\sum_{i=1}^{m} v_{i} x_{i_{0}}=1$

$v_{1} x_{1 j}+v_{2} x_{2 j}+K+v_{m} x_{m j}$

Where:

$\theta_{0}=$ The efficiency score of hospital 0

$x_{n j}=$ The amount of health system input $n$ utilized by the $j^{\text {th }}$ hospital

$Y_{m j}=$ The amount of health system output $m$ produced by the $j^{\text {th }}$ hospital

$U_{m}=$ The weight is given to health system output $m$

$V_{n}=$ The weight is given to health system input $n$

Source: Mujasi et. al. (2016)

As stated in Mujasi et al (2016) DEA faces one major shortcoming of producing efficiency scores that are susceptible to outlier-effect from DMUS [12] meaning that if there are few health centres which perform extremely well in the dataset, this will influence the efficiency scores of the rest of facilities. In either case, the results for the remaining Decision-Making Units become shifted towards lower efficiency levels, the efficiency frequency distribution becomes highly asymmetric, and the overall efficiency scale becomes nonlinear.

Thus, in this study, jack-knife analysis was used to test for the robustness of the Data Envelope Analysis technical efficiency measures and assess if extreme outliers were affecting the frontier and efficiency scores. While trying to avert the consequences of outlier-effect, we decided to drop each health centre that was highly efficient, taking one after the other, and re-estimating the efficiency scores until there was stability in the model. 


\section{Econometric Analysis (Tobit Regression Model)}

In the second stage of analysis, the DEA efficiency scores computed in the previous section were regressed against some institutional factors that affect or influence health facility management and some factors that within the environment of the same facility so as to measure their effect on how well efficient is the facility.

Thus, using the VRS technical efficiency scores as a dependent variable and given that the scores have upper-censor-limit (100\%), a Tobit regression model was used to estimate the adjusted efficiency scores for each health center, and this obtained estimates of the linear Tobit model, where the dependent variable is either zero or positive. Maximum likelihood method was applied, in this study, following the assumption that all normal disturbances of the model are homoscedastic. The following Tobit regression Model was used:

$\operatorname{Tobit}\left(\mathrm{Y}_{\mathrm{i}}\right)=\mathrm{a}_{0}+\alpha_{1} \mathrm{x}_{\mathrm{j} 1}+\alpha_{2} \mathrm{x}_{\mathrm{j} 2}+\alpha_{3} \mathrm{X}_{\mathrm{j} 3}+\mathrm{K}+\varepsilon_{\mathrm{j}} \ldots \ldots$

Where:

$Y_{j}=$ The variable return to scale efficiency score for the $\mathrm{j}^{\text {th }}$ hospital

$x_{j}=$ The explanatory variables

$\varepsilon_{\mathrm{j}}=$ The disturbance (error) term assumed to be normally distributed with mean $\mu$ and standard deviation $\delta$

$a=$ The Tobit coefficients indicate how a one-unit change in an independent variable alters the latent dependent variable. Sometimes, the values of the Tobit coefficients cannot be interpreted but their signs are very helpful for interpreting the results of the study.

Following Asbu [43], the Variable Returns to Scale DEA technical efficiency scores were transformed into inefficiency scores, left-censored at zero using the formula:

InefficiencyScore $=\left[\frac{1}{D E A-T E_{\text {_score }}}\right]-1$

The initially estimated general model contained all the identified explanatory variables and was:

Ineff $=a+\beta_{1}$ BOR $+\beta_{2}$ OPDIPD $+\beta_{3}$ ALOS $+\beta_{4}$ OWN $+\beta_{5}$ POPNCAT $+\beta_{6}$ SIZE $+\varepsilon_{i} \ldots 3.4$

Where $\beta$ is the vector of unknown parameters or coefficients; and $\varepsilon_{i}$ is the stochastic/random error term. I estimate the Tobit regression using STATA_13 for Windows ${ }^{\circledR}$. 
By estimating the empirical model, I will test two hypotheses; first, to test the overall significance of the model, where the joint null hypothesis was as follows:

$H_{0}: \beta_{1}=\beta_{2}=\beta_{3}=\beta_{4}=\beta_{5}=\beta_{6}=0$

And the alternative hypothesis was as follows:

$\mathrm{H}_{\mathrm{A}}: \beta_{1}=\beta_{2}=\beta_{3}=\beta_{4}=\beta_{5}=\beta_{6} \neq 0$ The joint null hypothesis was tested using the likelihood ratio test (LL).

Secondly, we tested the hypothesis that $\beta n$ is not significantly different from zero in either direction. Thus, the null $(\mathrm{Ho})$ and alternative hypotheses $(\mathrm{Ha})$ are: $\mathrm{Ho}: \beta n=0$ while $\mathrm{Ha}: \beta n \neq 0$

The t-distribution tests were preferred to measure the significance of each and every individual null hypotheses.

However, the objective was to estimate a parsimonious Tobit model that would help explain the observed inefficiencies. Such a model would be significant based on the Chi-Square. Thus, through an iterative process, several models were run containing various combinations of the explanatory variables.

The finally accepted model based on the Chi-Square was:

Ineff $=a+\beta_{1}$ BOR $+\beta_{2}$ OPDIPD $+\beta_{3}$ ALOS $+\beta_{4}$ OWN $+\beta_{5}$ POPNCAT $+\beta_{6}$ SIZE $+\varepsilon_{i}$

Based on past two-stage health facilities efficiency studies, I would expect a negative relationship between the Ineff and OPDIPD, and thus, $\beta_{2}$ is assumed to be a negative sign. Tobit coefficients indicate how a one-unit change in an independent variable xi alters the latent dependent variable Inefficiency.

\section{Data and Variable Choice}

This study used different sources of data of which some are primary (use of questionnaires) while other sources are secondary. The secondary sources consisted of Uganda hospital and HC IV Census data for 2014 [15] and the health sector data for FY2015/16 Financial year (July 1, 2015, to June 30, 2016) as reported by the $\mathrm{MOH}$ in the annual health sector performance report (AHSPR) [25] to explore the technical efficiency of health center IVs during that period.

In this study, the focus was put on HC IV Inputs and outputs. Data was assembled for 2 different inputs (HC IV staff, hospital beds) and 6 outputs (inpatient days, C-Sections, Blood Transfusions, deliveries, OPD visits, and immunizations). Based on the completeness of available data, the final selection was limited to 2 inputs and 3 outputs. The inputs included the total number of health center staff a proxy to labor and hospital beds a proxy to Capital. The outputs included outpatient visits, C-Sections performed, and inpatient days. It was assumed that this input-output mix elucidates most of the HCIV activities. The 
Caesarean sections were, for example, added to the mix because it is one of the major factors government considers while determining the functionality of HC IVs.

The choice of the variables (input, output, and explanatory) shown in Table 1 was guided by three considerations. First of all, past studies including Zere et. al. (2006) [26], Kirigia et. al. (2008) [27], and Tlotlego et. al. (2010) [28] that undertook efficiency of hospitals in Africa also employed similar inputs and outputs except for C-Section which was added specifically for Uganda's case. Secondly, the availability of relevant data in the ministry of health's annual health sector performance report for FY $2015 / 16$ [25] and the availability of data that is routinely compiled by hospitals to demonstrate ways in which the Uganda Ministry of Health can get additional informational value from such data without investing a lot of resources. 
Table 1

Description of the study variables for HCIVs $(n=30)$

\begin{tabular}{|c|c|c|c|}
\hline VARIABLE & DEFINITION & MEASUREMENT & DATA SOURCES \\
\hline \multicolumn{3}{|c|}{ Input Variables } & \multirow{5}{*}{$\begin{array}{l}\otimes \text { Questionnaires } \\
\otimes \text { Hospital and HC } \\
\text { IV Census report } \\
2014 \\
\otimes \text { Annual Health } \\
\text { Sector Performance } \\
\text { Report }\end{array}$} \\
\hline Labour & Staff/workers & $\begin{array}{l}\text { Total no. of health workers at the } \\
\text { facility year year }\end{array}$ & \\
\hline Capital & Beds & Total no. of beds in an HF in a year & \\
\hline Funds & Funding & Non-Wage $+\mathrm{PHC}$ in a given year & \\
\hline \multicolumn{3}{|c|}{ Output Variables } & \\
\hline IPD & Inpatient days & Total inpatient days in a year & \multirow{10}{*}{$\otimes F Y 2015 / 16$} \\
\hline OPD & Outpatient visits & Total outpatient visits made in a year & \\
\hline C-Sect & C-Sections & Total C-sections done in a year & \\
\hline Blood & Blood transfusions & Total blood transfusions done in a year & \\
\hline \multicolumn{3}{|c|}{ Explanatory Variables } & \\
\hline BOR & $\begin{array}{l}\text { Bed Occupancy } \\
\text { Rate }\end{array}$ & $\begin{array}{l}\text { The proportion of beds that were } \\
\text { occupied over a specific period }\end{array}$ & \\
\hline OPDIPD & $\begin{array}{l}\text { The proportion of } \\
\text { outpatients to } \\
\text { inpatients }\end{array}$ & $\begin{array}{l}\text { Total OPD visits divided by total } \\
\text { inpatient days in a year }\end{array}$ & \\
\hline ALOS & $\begin{array}{l}\text { Average Length of } \\
\text { Stay }\end{array}$ & $\begin{array}{l}\text { Dividing the total number of inpatient } \\
\text { days by the total admissions in a year }\end{array}$ & \\
\hline POPNCAT & $\begin{array}{l}\text { Catchment } \\
\text { Population }\end{array}$ & Total population in the catchment area & \\
\hline SIZE & Size of the hospital & $\begin{array}{l}\text { Proxy: Bed capacity of the facility where } \\
1=30 \text { beds and above while } \\
0=\text { otherwise }\end{array}$ & \\
\hline
\end{tabular}

The literature including Vladmanis (1992) [24], Rosko et. al. (1995) [29], and Zere et. al. (2006) [26] indicates that some of the factors that impact health facility efficiency include, catchment population, distance, location (urban/rural), ownership (profit/not-for-profit), teaching status, payment source (out-ofpocket/health insurance), occupancy rate, the average length of stay, outpatient visits as a proportion of inpatient days, and quality, and these were chosen as the explanatory variables for the health centre IV's efficiency. In this study, we selected the explanatory variables based on the availability of data as they are also described in Table 4.

We used labor to define staff/workers and the measurement was based on the total number of health workers at the facility, capital was defined as beds basing on the total number of beds in the health 
facility in a year as measurement. We, also, used funding and the measurement was total PHC funds allocated to the HF in a year.

Output variables were inpatient days which were defined as total inpatient days in a year, outpatient visits which were defined as total outpatient visits made in a year, C-Section defined as total C-Sections done in a year, and blood transfusions defined as total blood transfusions done in a year.

Explanatory variables were bed occupancy rate measured as a proportion of beds which were occupied over a specific period, proportion of outpatients to inpatients was measured as total OPD visits divided by the total number of inpatient days in a year, and catchment area was measured as the total population in the catchment area, average length of stay is measured by dividing the total number of inpatients days by the total admissions in the year and size of the hospital is measured by a bed capacity of the facility. The data collected on inputs, outputs, and explanatory variables were entered into a computer using Excel software from where STATA 13 was used to import and analyse this same data for all stages.

The research used largely the secondary data from Ministry of Health which was approved by the research committee since it did not contradict the ethics and regulations of the institution. The questionnaires which were open-ended were sent to selected health centre managers to give their opinions on the efficiency of the HC IVs and they were required to consent before filling the forms. The questionnaires did not have names or personal information that would link the respondent to opinion or information shared and that was to protect their privacy with guidance from SPEED INITIATIVE Program under Makerere University School of Public Health.

In summary, with supervision from Makerere University School of Public Health, we confirm that, in this study, all methods were performed in accordance with the relevant guidelines and regulations. The study went through all official protocols and was given a waiver by IRB which in this case was Makerere University School of Public Health and it was deemed unnecessary according to national regulations.

\section{Findings}

\section{Descriptive statistics of study variables}

Table 2 presents the descriptive statistics for inputs and outputs of HC IVs in this study's sample. During the study period, the minimum amount received for an HC IV was UGX 59m and the maximum UGX $130 \mathrm{~m}$, and thus they, on averagely, received UGX $97 \mathrm{~m}$ for a whole financial year which indicates a fair allocation for an HC IV. The number of beds was drastically apart with a minimum of 5 beds and a maximum of 74 beds in the selected facilities which clearly shows a high disparity that could lead to poor performance. This was the same as in the staffing case as the minimum number of staff was 10 and the maximum was 61.

On the other hand, the $30 \mathrm{HC}$ IVs received a Minimum of 13,939 , a maximum of 47,879 , and an average of 8,500 OPD visits. There was a minimum of 155 inpatient days, an average of 6,990 inpatient days, and 
a maximum of 26,471 inpatient days. The facilities conducted a minimum of Zero Caesarean Sections, 73.6 average Caesarean sections, and a Maximum of 742.

Table 2

Descriptive statistics of study variables for HCIVs $(n=30)$

The Input and Output Variables for HC IVs in Uganda FY2015/16

\begin{tabular}{|c|c|c|c|c|c|}
\hline VARIABLE & OBS & MEAN & STD. DEV. & MIN & MAX \\
\hline \multicolumn{6}{|l|}{ Inputs } \\
\hline Number of Staff & 30 & 29.3 & 12.5 & 10 & 61 \\
\hline Number of Beds & 30 & 37.7 & 17.9 & 5 & 74 \\
\hline Funds $(000,000)$ & 30 & 97 & 16 & 59 & 130 \\
\hline \multicolumn{6}{|l|}{ Outputs } \\
\hline Inpatient days & 30 & $6,990.5$ & $5,578.4$ & 155 & 26,471 \\
\hline Number of outpatient visits & 30 & $23,954.6$ & $8,500.4$ & 13,939 & 47,879 \\
\hline Cesarean Sections done & 30 & 73.6 & 146.2 & 0 & 742 \\
\hline
\end{tabular}

The Explanatory Variables for HC IVs in Uganda

VARIABLE

\section{Continuous Variables}

Funds $(000,000)$

Bed Occupancy Rate (BOR)

Outpatient visits as a ratio of Inpatient days (OPDIPD)

Average Length of Stay - days (ALOS)

\section{Categorical variables}

Catchment Population of HC IV (POPNCAT):

$1=$ less than 60,000 people \& $0=60,000$ people and above

Health Centre IV Size (SIZE):

$1=30$ beds and above \& $0=$ Less than 30 beds
OBS MEAN

STD. DEV.

MIN

MAX

30

97

16

59

130

30

47.17

25.49

8.49

98.00

30

9.31

19.12

1.13

105.35

$30 \quad 2.58$

1.29

1.18

7.005

For explanatory variables, $15 \mathrm{HC}$ IVs $(50 \%)$ had a catchment population of less than 60,000 and HC IVs $(50 \%)$ had a catchment area of more than 60,000 . For purposes of this study, $36.7 \%$ of the HC IVs in the study sample were small HC IVs (less than 30 beds) while the remaining $63.3 \%$ were large HC IVs. 
The bed occupancy rate varied from $8.49-98 \%$ with a mean of $47.17 \%$ and a standard deviation of $25.49 \%$. The proportion of outpatient department to inpatient days varied from $1.13-105.35 \%$ with a mean of $9.31 \%$ and standard deviation of $19.12 \%$. The average length of stay was 2.58 days with a standard deviation of 1.29 days and ranged between 1.18 to 7.00 days. Most patients do not exceed 3 days at the facility when admitted, they are either discharged or transferred to bigger hospitals for further management.

\section{Determination of efficiency using DEA}

Table 3 shows the HC IV DEA scores where 7 HC-IVs (23.3\%) Mukono, Dokolo, Wakiso, Rubaale, Bbale, Kakindo, and Kataraka were operating under constant returns to scale, implying that they were efficient (both pure technical and scale efficiency) concerning available sample. 19 of HC-IVs (63.3\%) were operating under increasing returns to scale, implying that a unit increase in the inputs of these HC IVs would result in a bigger proportionate increase in their health service outputs. These health centers would need to increase their size of inputs like labor and capital to achieve the optimal provision of healthcare services.

Four (04) of HC IVs (13.3\%) Bugangari, Luwero, Bugono, Anyeke were operating under decreasing returns to scale implying that a proportionate unit increase in inputs would have a detrimental effect on the health services outputs. 
Table 3

Output-oriented DEA Efficiency scores for HCIVs $(n=30)$ 2015/16

\begin{tabular}{|llll|}
\hline HEALTH FACILITY & CRS_TE & SCALE & RTS \\
\hline MUKONO_HC_IV & 1.00000 & 1.00000 & Constant Returns to Scale \\
\hline DOKOLO & 1.00000 & 1.00000 & Constant Returns to Scale \\
\hline WAKISO_HC_IV & 1.00000 & 1.00000 & Constant Returns to Scale \\
\hline RUBAALE_HC_IV & 1.00000 & 1.00000 & Constant Returns to Scale \\
\hline BBALE_HC_IV & 1.00000 & 1.00000 & Constant Returns to Scale \\
\hline KAKINDO_HC_IV & 1.00000 & 1.00000 & Constant Returns to Scale \\
\hline KATARAKA_HC_IV & 1.00000 & 1.00000 & Constant Returns to Scale \\
\hline NAKASONGOLA_HC_IV & 0.95366 & 0.95796 & Increasing Returns to Scale \\
\hline NSINZE & 0.91500 & 0.91500 & Increasing Returns to Scale \\
\hline BUKEDEA & 0.91089 & 0.98288 & Increasing Returns to Scale \\
\hline ISHONGORO_HC_IV & 0.89872 & 0.95642 & Increasing Returns to Scale \\
\hline BUGANGARI_HC_IV & 0.83900 & 0.99912 & Decreasing Returns to Scale \\
\hline RWASHAMAIRE_HC_IV & 0.80428 & 0.95862 & Increasing Returns to Scale \\
\hline BUDAKA & 0.80194 & 0.99981 & Increasing Returns to Scale \\
\hline KITWE_HC_IV & 0.67845 & 0.98620 & Increasing Returns to Scale \\
\hline KIYUNGA_HC_IV & 0.67637 & 0.95102 & Increasing Returns to Scale \\
\hline LUWERO_HC_IV & 0.61066 & 0.70743 & Decreasing Returns to Scale \\
\hline KIRUHURA_HC_IV & 0.58756 & 0.99961 & Increasing Returns to Scale \\
\hline BUGONO_HC_IV & 0.58214 & 0.79000 & Decreasing Returns to Scale \\
\hline ATIAK & 0.57360 & 0.99989 & Increasing Returns to Scale \\
\hline NTWETWE_HC_IV & 0.56656 & 0.99148 & Increasing Returns to Scale \\
\hline ANYEKE & 0.55170 & 0.69031 & Decreasing Returns to Scale \\
\hline BUKASA_HC_IV & 0.54455 & 0.83662 & Increasing Returns to Scale \\
\hline RUHOKO_HC_IV & 0.50922 & 0.94356 & Increasing Returns to Scale \\
\hline ORUM_HC_IV & 0.48999 & 0.96925 & Increasing Returns to Scale \\
\hline BULISA & 0.99952 & Increasing Returns to Scale \\
\hline BUVUMA_HC_IV & 0.88321 & Increasing Returns to Scale \\
\hline
\end{tabular}




\begin{tabular}{|llll|}
\hline HEALTH FACILITY & CRS_TE & SCALE & RTS \\
\hline ALEBTONG & 0.41272 & 0.64433 & Increasing Returns to Scale \\
\hline NGOMA & 0.37459 & 0.75573 & Increasing Returns to Scale \\
\hline KAKUMIRO_HC_IV & 0.35986 & 0.86242 & Increasing Returns to Scale \\
\hline
\end{tabular}

According to Table 3 and Figure 2, Health facilities like Bugangari, Luwero, Bugono, Anyek do not need to be added more resources because according to the study they are already receiving enough resources. The cause of their inefficiency could be either lack of staff motivation, poor administration, absenteeism, non-functionality of equipment, or other factors that could be leading to inefficiencies.

Those on increasing returns to scale need more resources to improve their efficiency so that they can perform at their optimal levels. Resources needed could be equipment, human resource, improvement in administration, and other factors that can improve efficiency in the health facility.

Those working at constant returns to scale like Kakindo, Bbale, Mukono, Wakiso, Dokoro, Rubaale, and Kataraka need to be expanded to the hospital level because they have reached their maximum capacity of the operation. Additional of more resources may not add any value in the actual sense. They are performing at their optimal levels given the sample available.

\section{Econometric Analysis of the determinants of inefficiency - Tobit Model}

From Table 4, the higher the health center IV's OPD is, the lower the predicted inefficiency score consistent with our a priori expectation and statistically significant at a 5 percent level of significance $(p>|t|=0.033)$. OPD with a coefficient of -0.0000338 means that a unit increase in OPD visits leads to a reduction in inefficiency by $0.00338 \%$

The Bed Occupancy Rate (BOR) has a negative sign indicating that the higher the bed occupancy rate the higher the efficiency score. In other words, a 1\% increase in Bed Occupancy Rate (BOR) increases the efficiency score by $2.12 \%$ while holding all other factors in the model constant. The score coefficient is statistically significant at a $5 \%$ level $(p<0.05)$.

The size of HC IV, according to this study analysis, is not a significant factor in explaining health center inefficiency. The results indicate that the predicted inefficiency score for big HC IVs is 0.252 points lower than the reference category of small HC IVs (those with less than 30 beds) when all other factors are held constant.

The coefficient for ALOS (0.0906) has a positive sign and statistically not significant at the 5 percent level $(p>|t|=0.427)$. This means that a unit increase in the average length of stay of patients at the HC IV leads to a decrease in efficiency of $9 \%$, holding all other variables constant. The higher a health center's ALOS, the lower the predicted inefficiency score 
With regards to catchment population (POPNCAT, results point out that the predicted inefficiency score for HC IVs with less than 60,000 people in their official catchment area is 0.3982 points lower than for the counterparts (those with at least 60,000 people in their catchment area) when all other factors are held constant. This shows that HC IVs with lower catchment areas have lower inefficiencies compared to their counterparts with higher population areas. However, it should be noted that in this study findings indicate that the catchment population of HC IV is not statistically significant.

The coefficient for financing has a positive sign and is not statistically significant at a 5 percent level $(p>|t|=0.891)$. This means that a unit increase in the financial resources at health center IV does not affect its efficiency.

Table 4: Tobit model results for HCIVs ( $n=30)$ 2015/16

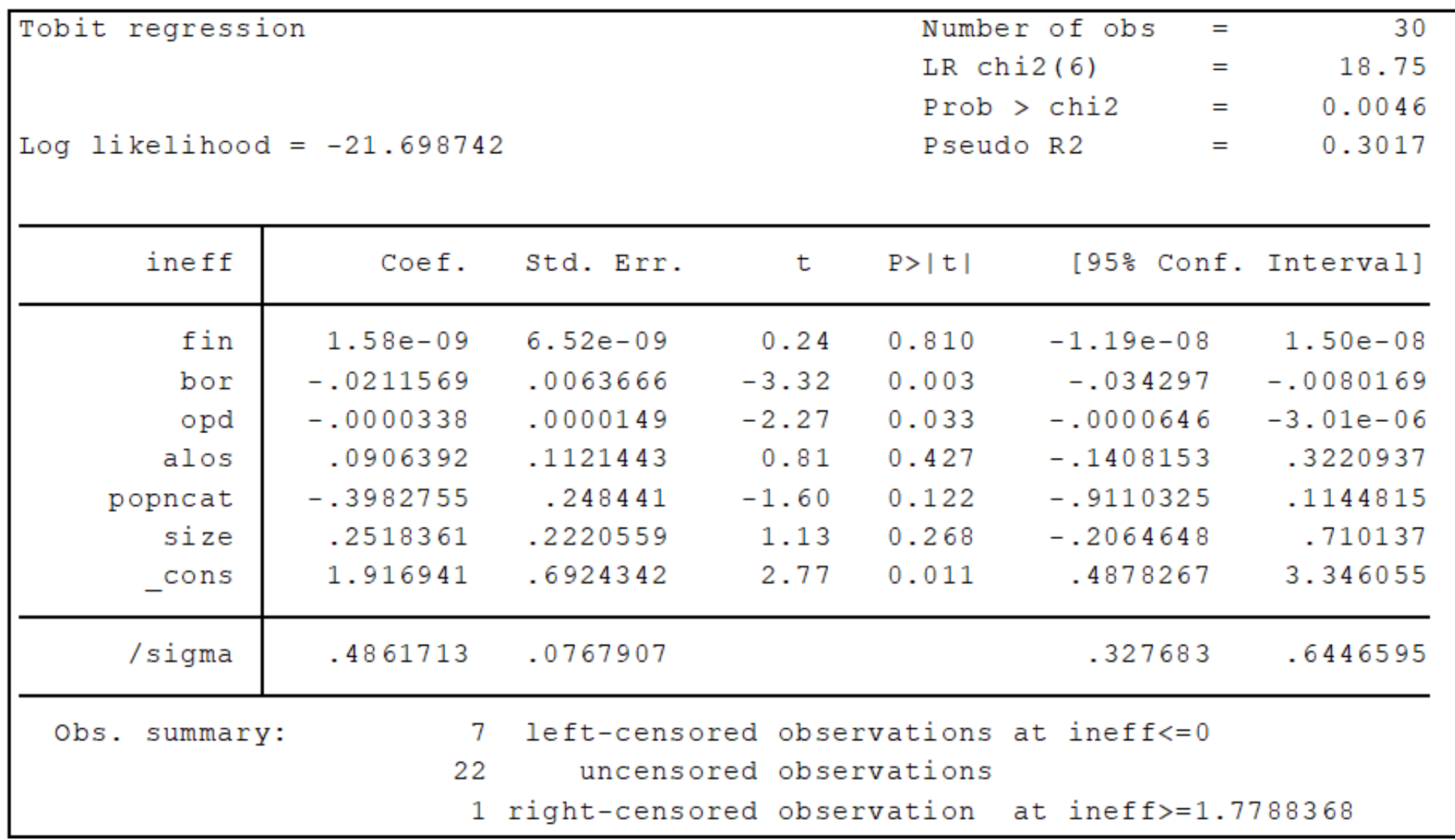

\section{Discussion Of Findings}

Whereas some variables in the model are not statistically significant at a $95 \%$ level of confidence their combination in the Tobit model is highly significant with the probability of $\mathrm{Chi}^{2}[0.0046]$ less than 0.05 .

In this study, we needed to answer the following question: how resources are efficiently utilized at HC IVs in Uganda, and what resource mix would make HCIVs in Uganda more efficient? The sub-questions are: what is the technical and scale efficiency of health facilities (HC IVs) in Uganda FY 2015/2016 and how do institutional and contextual/environmental variables affect the efficiency of HC IVs in Uganda? The study used DEA and Tobit models to answer the research questions. In this section study findings, 
theoretical and empirical literature, and my understanding of the Ugandan health context are utilized to discuss and come up with recommendations.

This study shows that efficiency remains a challenge at Ugandan Health Centre IVs. We show that most of the health facilities would require additional inputs to drive the efficiency higher (i.e. the facilities at increasing returns to scale) while for some other identified facilities that are at decreasing returns to scale, the increase in inputs needs to be done together with other measures to drive efficiency within the health facility.

This study shows despite facing similar resource-constrained conditions, that define developing countries like Uganda, with similar inputs, some HC IVs are more successful than some of their counterparts in converting available inputs to desired outputs. We show that facility efficiency is associated with high productivity (as shown by both the outpatient day visits and bed occupancy rate) while the long average length of stay (potentially indicative of complicated case-mix) is associated with lower levels of efficiency.

The application of Data Envelope Analysis to assess the efficiency of health facilities in Africa has increased in recent years. This study contributes to a growing literature on efficiency analysis in Africa generally and specifically to incipient literature on health center efficiency in Uganda. The last published Data Envelope Analysis study in Uganda was on hospitals and it reports an average technical efficiency score of $91.4 \%$. No study in Uganda has focussed on HCIVs despite their importance in our health system. While it is not feasible to compare the true efficiency of hospitals across settings because the technical efficiency scores are calculated concerning the frontier of efficiency in each sample and given that they focused on hospitals and this study focused on HC IVs, it is important to recognize that the average technical efficiency score of $63.5 \%$ reported in this study is lower than that reported in Kenya and Tanzania. Similar studies in Uganda's neighbors Kenya (Kirigia et al., 2002) [30] and Tanzania (Kembo, 2015) [31] found average technical efficiency scores of $95.6 \%$ and $76.9 \%$ respectively. The Kenya study [30] focussed on public hospitals while the Tanzania study [31] focusing on faith-based hospitals (private not profit).

The findings on factors associated with efficiency are in line with findings from other countries. The findings are in line with (Coyne et al., 2009) [32] who also show that a high BOR is associated with increased efficiency. However, this finding on BOR needs to be contextualized as findings from other countries (the United Kingdom and Australia) have instituted a target occupancy rate as there was evidence that rates exceeding $85 \%$ in acute care hospitals are associated with problems in handling both emergency and elective admissions were not ideal for infection control and ensuring quality of care.

\section{Policy Implications basing on findings}

Based on the findings presented above, we draw the following implications for policymakers involved in developing strategies for ensuring that all health facilities are made more efficient: 
- We note that most facilities are under-resourced and hence providing additional resources would be critical to improving their efficiency. The focus on increasing resources should be to those that directly affect the production process such as human resources, infrastructure, and medical supplies. For instance, most of these facilities are operating below their set norms.

- For the facilities identified to be operating under decreasing returns to scale, policymakers need to ensure that any additional investments are followed by addressing within-facility factors that may impact the productivity of the facility and it is best done for each facility as an independent case.

There is a need to institutionalize monitoring of efficiency measurement within the routine performance assessment of the Ministry of Health as part of the broader framework of performance management

\section{Limitations of the study}

1. This study assesses technical efficiency but does not attempt to address allocative efficiency. This is an area that future studies could consider.

2. The study also does not address issues of long-term productivity and only provides a snapshot of efficiency but there could be changes over time influenced by various factors.

In an expanded efficiency study, more analysis would be made to get the input reductions and/or output increases that would have been required to make the individual pure technically inefficient HC IVs efficient. Future studies could also look at the optimal inputs required to obtain the desired inputs and hence inform the revision of staffing and funding norms where need be.

\section{Conclusion}

The findings provided empirical evidence of the technical efficiency of the sampled HC IVs. The study also identified some of the factors that influence the attainment of efficiency among HC IVs. As policymakers focus on increasing access to health services, there is a need to address efficiency in providing these services. In addition to pushing strategies for ensuring efficiency to maximize the use of the scarce resources, there is a need to further interrogate within facility factors that may impact service delivery. This will be critical in addressing unmet needs especially for maternal health services which these HC IVs are supposed to provide.

The inappropriate size of an HC IV (too large or too small) may sometimes be a cause of technical inefficiency and many take this as scale inefficiency where it can be best described as either increasing returns-to-scale or decreasing returns-to-scale. Decreasing returns to scale (also known as diseconomies of scale) implies that a health center is too large for the volume of activities that it conducts. Unit costs increase as outputs increases. In contrast, a health center with increasing returns to scale (economies of scale) is too small for its scale of operation. Unit costs decrease as outputs increase. A Health Centre that is scale-efficient is said to operate under constant returns to scale. 


\section{Abbreviations}

AE Allocative Efficiencies

AHSPR Annual Health Sector Performance Report

ALOS Average Length of Stay

BOR Bed Occupancy Rate

C-Section Caesarean Sections

DEA Data Envelopment Analysis

DMU Decision-Making Unit

FY Financial Year

HC IV Health Center IV

HF Health Facility

HSD Health Sub-District

HSDP Health Sector Development Plan

LP Linear Programming

$\mathrm{MOH}$ Ministry of Health

NRH National Referral Hospital

OPD Out-Patient Department

PHC Primary Health Care

PNFP Private-Not-For-Profit

RRH Regional Referral Hospital

SDGs Sustainable Development Goals

TE Technical Efficiency

UHC Universal Health Coverage

UNMHCP Uganda National Minimum Health Care Package 


\section{Declarations}

\section{Ethics approval and consent to participate}

The research used largely the secondary data from Ministry of Health which was approved by the research committee since it did not contradict the ethics and regulations of the institution.

The questionnaires which were open-ended were sent to selected health centre managers to give their opinions on the efficiency of the HC IVs and they were required to consent before filling the forms. The questionnaires did not have names or personal information that would link the respondent to opinion or information shared and that was to protect their privacy with guidance from SPEED INITIATIVE Program under Makerere University School of Public Health.

In summary, with supervision from Makerere University School of Public Health, we confirm that, in this study, all methods were performed in accordance with the relevant guidelines and regulations. The study went through all official protocols and was given a waiver by IRB which in this case was Makerere University School of Public Health and it was deemed unnecessary according to national regulations.

\section{Consent for publication}

All tables, graphs and charts in this paper are original and were done by Authors. This means that the "Consent for Publication" from another source is NOT APPLICABLE

\section{Availability of data and material}

The data set generated to use in this study was obtained from a government database and when needed, it can be availed through right channels. The dataset used can be obtained from Mr. Ahimbisibwe Expeditus on email expeditus2010@gmail.com .

\section{Competing interests}

The Authors declare that they have no competing interests

\section{Funding}

The Authors prepared this manuscript by themselves and were not paid to do this. 


\section{Authors' contributions}

All Authors read participated equally to generate this article, have read and approved the manuscript and therefore, they give consent for this manuscript to be published. The responsibilities assigned to each Author during the preparation of the manuscript are as follows;

E.A: Writing of the main manuscript text and gathering data, linking data to methodology and policy analysis/implications

E.T.R: Data cleaning, management, modelling, analysis of data using STATA and interpretation of statistical findings.

C.T.K: Reviewing Literature, linking literature to methodology and interpretation of policy implications basing on statistical findings

\section{Acknowledgements}

The SPEED Initiative in Uganda is acknowledged for funding the Fellowship Programme in Health Systems Management from whose research this manuscript is prepared. The authors also acknowledge Uganda Bureau of Statistics (UBOS), Ministry of Health, Makerere University School of Public Health and World Health Organization who provided data sets necessary for the analysis and provided assistance in understanding the data.

\section{References}

1. World Health Organization. World health statistics 2016: monitoring health for the SDGs, sustainable development goal. Geneva - Switzerland: World Health Organization, 2016. Google Scholar

2. National Planning Authority (NPA) (2015): Second National Development Plan (NDPII) 2015/16 2019/20 [http://npa.go.ug /wp-content/uploads/NDPII- Final. pdf ]

3. Ministry of Health (MOH) (2010): The Second National Health Policy - Promoting People's Health to Enhance Socio-economic Development [http://library.health.go.ug/sites/default/files/resources/Second\%20National\%20Health\%20Policy\% 202010. pdf ]

4. Ministry of Health (MOH) (2015): Health Sector Development Plan 2015/16 - 2019/20. [https://health.go.ug/sites/default/files/Health\%20Sector\%20Development\%20Plan\%20201516_2019-20.pdf ]

5. World Health Organization. State of health financing in the African region. Geneva: World Health Organization; 2013. [https://www.afro.who.int/sites/default/files/2017-06/state-of-health-financingafro.pdf ] 
6. Advocates Coalition for Development and Environment (ACODE) (2016): Health Spending in Uganda - Implications on the National Minimum Healthcare Package. ACODE Policy Briefing Paper Series (32). [https://media.africaportal.org/documents/PBP_32.pdf ]

7. Hensher M. (2001): "Financing the Health System through Efficiency Gains." Background paper prepared for Working Group 2 of the Commission on Macroeconomics and Health. Geneva: World Health Organization.

8. Ministry of Health (MOH) (2016): Annual Health Sector Performance Report FY 2015/16. [https://www.health.go.ug/cause/the-annual-health-sector-performance-report-2015-16/ ]

9. Government of Uganda (2009): National Health policy-Reducing Poverty through improving people's health. Kampala: Ministry of Health.

10. Ministry of Health (MOH) (2015): Health Sector Development Plan (2015/16 - 2019/20). [https://health.go.ug/sites/default/files/Health\%20Sector\%20Development\%20Plan\%20201516_2019-20.pdf ]

11. Yawe B. (2010): Hospital performance evaluation in Uganda: a super-efficiency data envelope analysis model. Zambia Soc Sci J. 2010; 1 (No.1): Article 6.

12. Mujasi, P.N., Asbu, E.Z. \& Puig-Junoy, J. (2016): How efficient are referral hospitals in Uganda? A data envelopment analysis and Tobit regression approach. BMC Health Serv Res 16, 230 (2016). https://doi.org/10.1186/s12913-016-1472-9

13. Zere E, Mcintyre D, Addison T. (2005): Hospital efficiency and productivity in three provinces of South Africa. South Afr J Econ. 2005; 69:336-58. [https://onlinelibrary.wiley.com/doi/abs/10.1111/j.18136982.2001.tb00016.x ]

14. Charnes, A., Cooper, W. W., \& Li, S. (1989). Using data envelopment analysis to evaluate efficiency in the economic performance of Chinese cities. Socio-Economic Planning Sciences, 23(6), 325-344. [http://www.pik-potsdam.de/ luedeke/R_Kram/DEA/lit/1-s2.0-0038012189900013-main.pdf ]

15. Ministry of Health (MOH) (2014): Uganda Hospital and Health Centre IV Census Survey. [https://www.who.int/healthinfo/systems/SARA_H_UGA_Results_2014.pdf ]

16. Coelli T, Prasada Rao DS, O'Donnell CJ, Battese GE. An Introduction to Efficiency and Productivity Analysis. 2nd Ed. New York: Springer; 2005.

17. Kumbhakar CS and Lovell CAK (2000): Stochastic Frontier Analysis. Cambridge; Cambridge University Press

18. Parkin, D., \& Hollingsworth, B. (1997). Measuring production efficiency of acute hospitals in Scotland, 1991-94: validity issues in data envelopment analysis. Applied Economics, 29(11), 1425-1433.

19. Hollingsworth B \& Parkin D. (1998) Developing efficiency measures for use in the NHS, A report to the NHS Executive Northern \& Yorkshire R\&D Directorate, February 1998, Health Economics Group, University of Newcastle.

20. Zainal N.S, and Ismail M. Concept and measurement of efficiency (2010): A Review, Voice of Academia. 2010; 5 (1): 17-26 
21. Farell M.J. (1957): Measurement of productive efficiency. J. Royal Statistical Soc. Series. 1957; 3: p.253-290. [https://doi.org/10.2307/2343100]

22. Koopmans T.C. (1951): An analysis of production as an efficient combination of activities. In Koopmans, T. C., editor, Activity Analysis of Production and Allocation. John Wiley and Sons, Inc. 1951.

23. Charnes A, Cooper W.W, Rhodes E. (1978): Measuring the efficiency of decision-making units. European Journal of Operational Research. 1978; 2(6): 429-444.

24. Vladmanis V. (1992): Sensitivity analysis for DEA models: an empirical example using public vs NFP hospitals. J Public Econ. 1992; 48:185-205

25. Ministry of Health (MOH) (2016): Annual Health Sector Performance Report for FY2015/16. [https://www.health.go.ug/cause/the-annual-health-sector-performance-report-2015-16/ ]

26. Zere E, Mbeeli T, Shangula K, Mandlhate C, Tjivambi K, Kapenambili W. Technical efficiency of district hospital (2006): evidence from Namibia using data envelopment analysis, Cost Effectiveness and Resource Allocation. 2006; 4(5), Available at: [http://www.resourceallocation.com/content/pdf/14787547-4-5.pdf ]

27. Kirigia J.M, Emrouznejad A, Cassoma B, Asbu E.Z, Barry S (2008): A Performance assessment method for hospitals: The case of a municipal hospital in Angola", Journal of Medical Systems. 2008; 32(6): 509-519.

28. Tlotlego N, Nonvignon J, Sambo L.G, Asbu EZ, Kirigia J.M (2010): Assessment of productivity of hospitals in Botswana: a DEA application. Int Arch Med. 2010; 3:1-14

29. Rosko M.D, Chilingerian JA, Zinn J.S, Aaronson W.E (1995): The effects of ownership, operating environment, and strategic choices on nursing home efficiency. Med Care. 1995; 33:1001-21

30. Kirigia J.M, Emrouznejad A, Sambo L.G. (2002): Measurement of technical efficiency of a public hospital in Kenya: using data envelopment analysis", Journal of Medical System. 2002; 26(1): 39-45.

31. Kembo M. Bwana (2015): Measuring Technical Efficiency of Faith-Based Hospitals in Tanzania: An application of Data Envelopment Analysis (DEA) Research in Applied Economics ISSN 1948-5433 2015, Vol. 7(1)

32. Coyne S, Short R, and Singh S. (2009): Hospital cost and efficiency - do hospital size and ownership type really matter? Journal of healthcare management / American College of Healthcare Executives 54(3):163-74; discussion 175-6 - May 2009

33. Kumar, S. and Gulati, R. (2008), "Evaluation of technical efficiency and ranking of public sector banks in India: An analysis from cross-sectional perspective", International Journal of Productivity and Performance Management, Vol. 57 No. 7, pp. 540-568. https://doi.org/10.1108/17410400810904029

34. Chen, C. M., \& Zhu, J. (2011). Efficient resource allocation via efficiency bootstraps: An application to R\&D project budgeting. Operations Research, 59(3), 729-741.

\section{Figures}




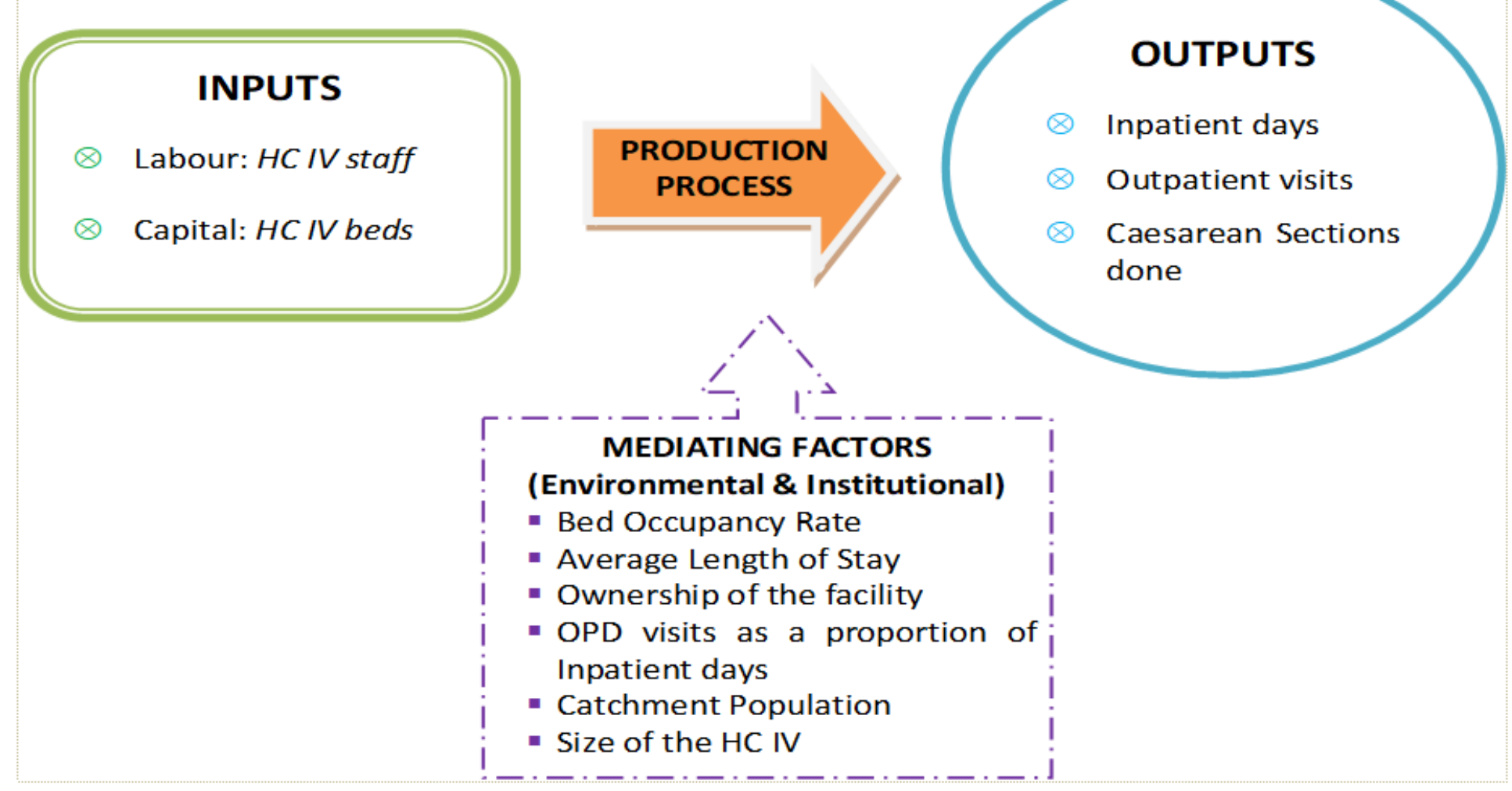

Figure 1

Production Process of HC IVs in Uganda 


\section{GRAPH SHOWING CRT- TE AND SCALE EFFICIENCY}

1.2

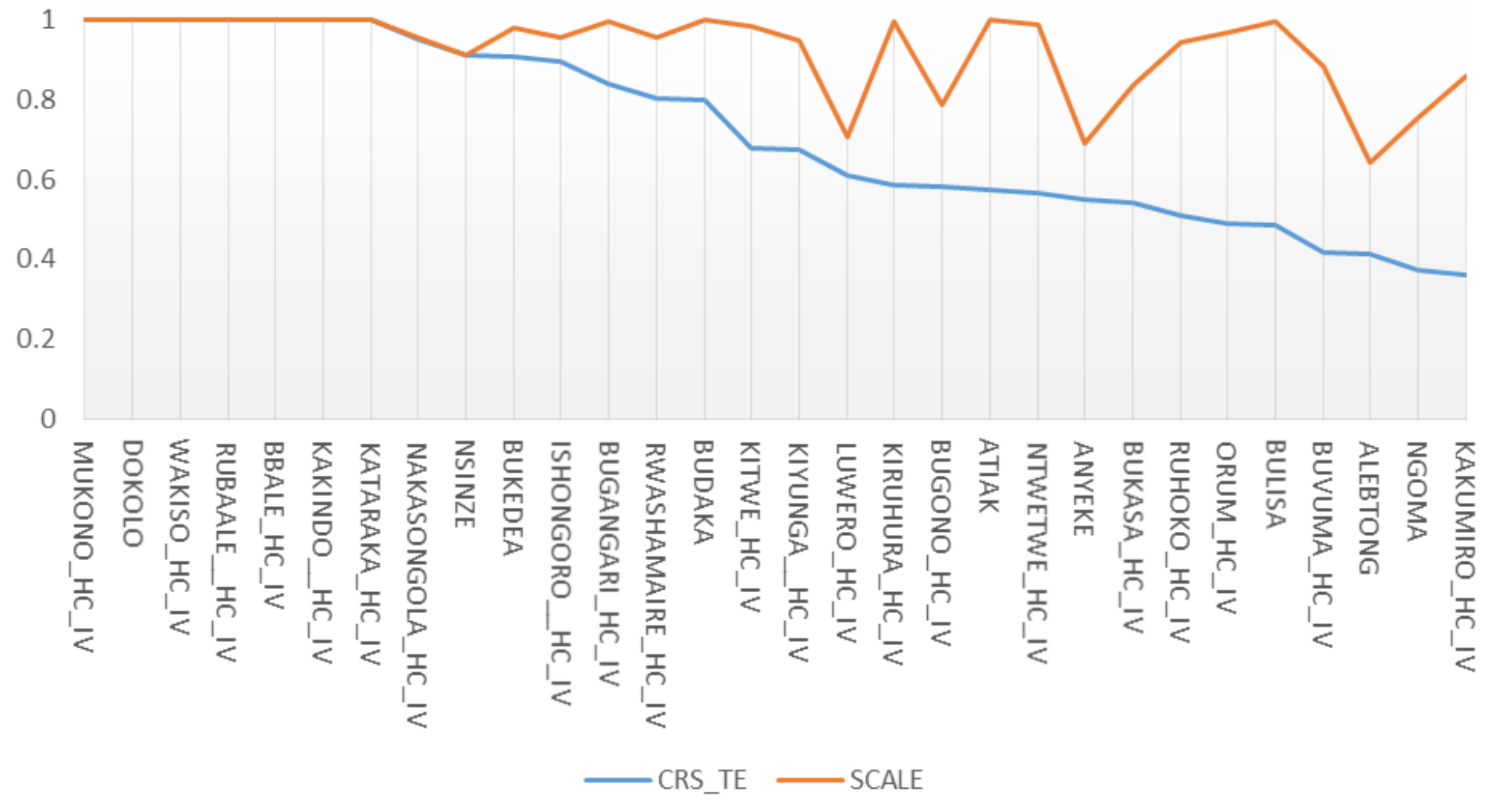

Figure 2

Graph showing CRT-TE and Scale Efficiency for HCIVs in Uganda

\section{Supplementary Files}

This is a list of supplementary files associated with this preprint. Click to download.

- AppendixIDEAOutputforHCIVsinUganda.docx 